\title{
BONDING OF ZIRCONIA SUPERSTRUCTURE TO ONE-PIECE TITANIUM AND ZIRCONIA IMPLANTS WITH DIFFERENT LUTING AGENTS
}

\author{
Mahy H. Hassouna* and Lamia Dawood**
}

\begin{abstract}
Purpose: This in-Vitro research was performed to determine how zirconia and titanium onepiece implants are bonded to zirconia superstructure crown using different luting cements.

Materials and methods: sixty-four zirconia ceramic superstructure (ceramill zolid) were bonded to thirty-two one-piece titanium implants and thirty-two one-piece zirconia implants, using four different luting agents: group GI: glass-ionomer cement, group RG: resin-modified G.I, group SA: self-adhesive resin cement and group CR: conventional resin cement. Subsequently to thermocycling $\left(5^{\circ} \mathrm{C}\right.$ to $55^{\circ} \mathrm{C}$ water over a 15,000 -cycle span, with a dwell time of 15 seconds), the crowns were detached vertically (pull-out test) with a Universal Testing machine. Post Hoc Tukey test was used to detect pairs of comparisons. One-way ANOVA test was used for statistical analysis.

Results: The titanium and zirconia groups differed significantly $(P<.001)$. With titanium specimens the average bond strength values were higher than in the zirconia specimens. The highest reported value was for the conventional resin cement group (CR) of titanium implants $(630.38 \pm 83.0 \mathrm{~N})$ while the lowest one was reported for glass ionomer cement $(\mathrm{GI})$ of zirconia implants $(129.64 \pm 15.94 \mathrm{~N})$.

Conclusions: The proper selection of a luting agent when bonding zirconia ceramic superstructure onto one-piece zirconia implants is important. Conventional resin cements and self-adhesive cements could be used for bonding of zirconia superstructure for both titanium and zirconia implants.
\end{abstract}

KEYWORDS: One-piece implant, Bonding, Adhesive cements, Titanium, Zirconia.

* Assistant Professor, Fixed Prosthodontics Dept., Faculty of Dentistry, Mansoura University, and Delta University for Science and Technology, Egypt.

**Associate Professor, Fixed Prosthodontics Dept., Faculty of Dentistry, Mansoura University, and Delta University for Science and Technology, Egypt. 


\section{INTRODUCTION}

Over the last decades titanium implants are considered the gold standard material in oral implantology. ${ }^{1}$ Titanium has positive characteristics as biocompatibility, great mechanical strength and high survival rate clinically, however, the gray color of titanium may be a challenging in esthetic area. ${ }^{2}$ Mainly failure of titanium implants may be a consequence of considerable titanium ions release, which was proven by studies on animals where titanium particles were found in macrophages and local lymph nodes. ${ }^{3-5}$ Monolithic zirconia and yttriastabilized tetragonal zirconia polycrystal ceramics (Y-TZP) was used as restorative materials to improve esthetics instead of metallic ones, as most patients rejected metal restorations and inquired for esthetic replacement of missed teeth. Nevertheless, zirconia was used recently for fabrication of dental implants. Zirconia was reported to have comparable biological properties and equivalent degree of survival parallel to the standard titanium alloy (Ti6Al-4V) implants. ${ }^{6,7}$ In terms of its biological and mechanical properties, low thermal conductivity, high fracture toughness (high elastic module), ${ }^{8}$ and low bacterial adhesion ${ }^{9}$ in addition to high esthetic, zirconia has shown to be superior to other ceramic materials. Even with small implant diameter, onepiece zirconia dental implants showed clinically acceptable mechanical properties. ${ }^{10}$

Zirconia dental implants are situated in anterior esthetic zone in cases of traditional healed edentulous position, ${ }^{11}$ in immediate extraction place, and immediate temporization. ${ }^{12}$ Several investigations established that osseointegration of zirconia implants is not lower in comparison to titanium implants with well-recognized coarse surfaces. ${ }^{1,13,14}$ Most of currently available zirconia implants are one-piece system which exhibited a great degree of survival, constant mucosal margin levels and marginal bone integrity after 5 years in utility. ${ }^{15}$ Although long-term clinical studies are rare, the initial studies show survival rate of $95.6 \%$ after one year ${ }^{16}$ and $95 \%$ five years follow up. ${ }^{17}$ Nowadays, the usage of zirconia implants is expanded by the increased needs for metal-free implants and prostheses, and positive outcomes from clinical and preclinical investigations. ${ }^{18}$ So, most of dental specialists expected that in the close future, zirconia oral implants will be concurrent with titanium implants. ${ }^{19}$

One-piece implant design was invented to overcome the defective structure strength present in the two-piece design. ${ }^{16}$ The unique design of this implant provides several advantages such as high mechanical strength, more simple surgical technique, no microgap between implant and abutment, and similar to the conventional crown and bridge procedures. ${ }^{20}$

Retention of the superstructure to one-piece implant depends on several factors, such as implant form, cement type and surface treatments. ${ }^{21-23}$ As zirconia has high strength, ${ }^{8}$ it can be bonded using zinc phosphate cement, glass ionomer cement or resin modified glass ionomer cement. ${ }^{24}$ Nonetheless, the retention force of restorations could be improved when using resin cements. ${ }^{25}$ Additional problems existed for sufficient bonding if the prosthetic material is zirconia, this is due to its high crystalline content and absence of glass, ${ }^{26}$ which make it resistant to hydrofluoric acid etching. ${ }^{27}$ Zirconia needs alternative surface treatments compared to other glassmatrix ceramics because retention-loss is an important problem affecting the clinical success rate. ${ }^{28,29}$ Air-borne particle abrasion was used to improve the mechanical bond strengths of zirconia. ${ }^{30}$

Silane coupling is an alternative technique of enhancing bonding strength via chemical way but, it may be ineffective with zirconia as it does not contain silica. ${ }^{31}$ The strength of bonding to zirconia increased after silica coating followed by silane application; ${ }^{32}$ however, after thermocycling it declined in strength. ${ }^{33}$ 
It was concluded that the usage of primers or resin cements containing 10-methacryloyloxydecyl dihydrogenphosphate (MDP) monomer subsequent to air-borne particle abrasion improved the adhesion to zirconia. ${ }^{30,34} \mathrm{MDP}$ is an acidic phosphate monomer, which was initially used to adhere to metal oxides then, it was used for zirconia. ${ }^{35}$ Its affinity to metal oxides and zirconia surface is simply shielded with a passive oxide layer, which makes zirconia like metal, as a result it can be used to improve the adhesion of resin cement to zirconia. ${ }^{36}$

Different techniques were used to calculate bonding force between materials either macro or micro specimens: tensile tests, shear tests, or push-out tests. ${ }^{37,38}$ Different bonding methods to zirconia ceramic and titanium have been stated, ${ }^{39}$ nevertheless, few researches were done comparing retention of zirconia crowns to both types of one piece implants using different types of luting cements..$^{40-42}$ So, this study aimed to estimate the impact of various luting agents on the retention force of zirconia ceramics to different one-piece implants. The postulated null hypotheses were that: (1) Cement type may influence the pull-out retention values; (2) Type of implant also might influence the pull-out retention values.

\section{MATERIALS AND METHODS}

In the current study, 32 one-piece titanium implants (T) (Bredent ${ }^{\circledR}$ whiteSKY) and 32 onepiece zirconia implants $(\mathrm{Z})$ (Bredent ${ }^{\circledR}$ whiteSKY) with $4.5 \mathrm{~mm}$ diameter and $10 \mathrm{~mm}$ length were used. The endosseous part of the implants were inserted inside transparent epoxy resin blocks (Kemapoxy 150, CMB chemicals, Egypt) using a specially designed centralizing device to hold the implant during fixation (Figure 1). It consisted of cylindrical Teflon mold $(2.5 \mathrm{~cm}$ height and $2 \mathrm{~cm}$ diameter) fixed on a copper ring with a hole in its center with the same dimension of the implant head $3.4 \mathrm{~mm}$ diameter and $6 \mathrm{~mm}$ length, two inner separate halves of Teflon ring were fixed inside the outer Teflon ring for easy separation. This device was used to guide the positioning of the implant within the center of the epoxy resin block.

Implants were scanned with an optical scanner (Ceramill map400, Amman Girrbach, Germany). Using the special software (Ceramill Mind design software), a mandibular right first premolar crown was designed with a bar on the occlusal surface to simplify its removal after cementation. ${ }^{42}$ A cement space of $50 \mu \mathrm{m}$ was planned for cementation, starting $1 \mathrm{~mm}$ away from the margins. Sixty-four zirconia ceramic crowns (ceramill zolid, Amman Girrbach, Germany) were dry milled using the 5-axis milling machine (Ceramill Coolstream, Amman Girrbach, Germany). Sintering of the crowns was done according to the manufacturer's recommendations using the sintering furnace (Programat P500, Ivoclar Vivadent, Liechtenstein). The ceramic glaze (Ceramill glaze Amman Girrbach, Germany) was applied over the crowns and fired according to the manufacturer's recommendations. The fitting surface of all crowns was subjected to air-borne particle abrasion with $50 \mu \mathrm{m} \mathrm{Al}_{2} \mathrm{O}_{3}$ at right angle to the surface at distance of $10 \mathrm{~mm}$ and 2 bars pressure for 20 seconds. All implants and crowns were ultrasonically cleaned for 4 minutes in a 96\% ethanol ultrasonic bath (TPC-15; Telsonic, Bronschhofen, Switzerland). ${ }^{40,43}$ Retention of zirconia crowns to titanium and zirconia implants was examined using four different types of cements; group GI: Glass-ionomer cement (Ketac Cem, 3M-ESPE, USA), group RG: Resin-modified glass ionomer (RelyX Luting Plus, 3M-ESPE, USA), group SA: Self-adhesive resin cement (RelyX U200, 3M-ESPE, USA), and group CR: Conventional resin cement (RelyX Ultimate, 3M-ESPE, USA). With conventional resin cement groups (CR), before cementation, a universal primer containing 10-MDP (Z-PRIME Plus, Bisco Inc, Schaumburg, USA) was coated by disposable brush inside the fitting surface of the crowns, and titanium and zirconia implant 
abutment portions according to manufactures' recommendations. The primer was left on the bonding surfaces for 60 seconds till reaction occurs, then, the specimens were dried using oil-free air for 5 seconds to remove any excess primer.

Each zirconia crown in each group was filled with its corresponding cement and placed on its implant under $3 \mathrm{~kg}$ constant load applied perpendicular to the long axis of the specimen for 10 minutes using a cementation device to ensure good seating. Light curing was used for 20 seconds (Valo Cordless, Ultradent, South Jordan, UT, USA) for resin cement groups. Subsequently, the specimens were incubated in $37^{\circ} \mathrm{C}$ water path for 24 hours. After water storage, specimens were thermocycled in $5^{\circ} \mathrm{C}$ to $55^{\circ} \mathrm{C}$ water over a 15,000-cycle span, with a dwell time of 15 seconds (THE-100 SD Mechatronic Thermocycler, Germany).

\section{Pull-out retention test}

Each crown was attached to the upper moving holder of the Universal Testing machine (Instron, Model 3345, Norwood, MA, USA) through the occlusal bar (Figure 2) and subjected to vertically dislodging force along the apico-occlusal axis using a load cell of $5 \mathrm{kN}$ at a crosshead speed of $0.5 \mathrm{~mm} / \mathrm{min}$. till crown debonding occurred and load dropped. The maximum retention force at dislodgment (in Newton) was recorded.

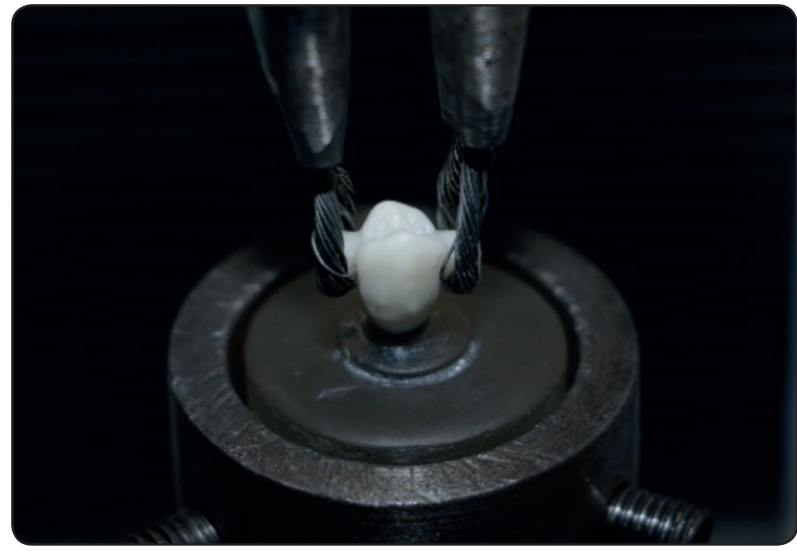

Fig. (2): Crown debonding by the Universal Testing machine.

Assessment of the debonding failure modes was done by optical examination of the abutments and crowns using a digital stereomicroscope at X25 magnification (Olymbus Model SZ2-ILST, Japan) with a corresponding digital camera and software.

Failure mode was recorded with the following parameters:

I. Adhesive failure: If less than $25 \%$ of cement content was on the surface of the abutment.

II. Cohesive failure: If more than $75 \%$ of the cement content is on the surface of the abutment.

III. Mixed (adhesive/cohesive) failure: If less cement material was present on the surface of the abutment. ${ }^{24}$

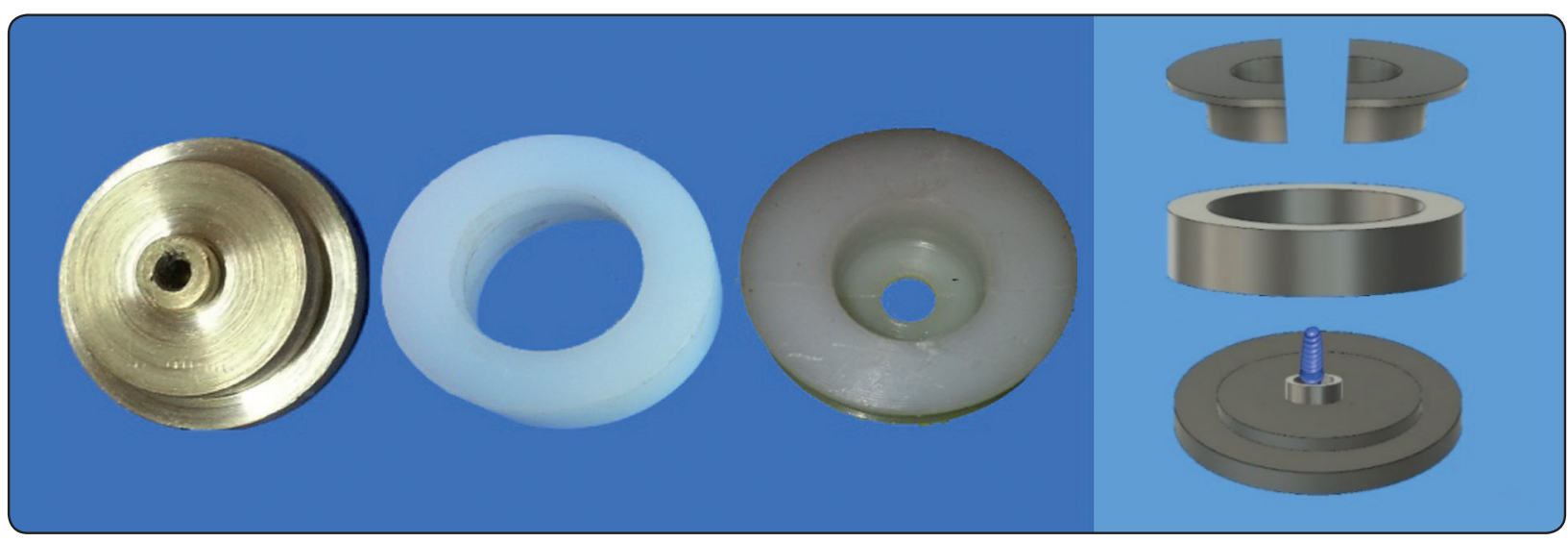

Fig. (1): Specially designed centralizing device. 


\section{Statistical Analysis}

The statistical analysis of data was done using IBM SPSS Corp. Released 2013 (IBM SPSS Statistics for Windows, Version 22.0. Armonk, NY: IBM Corp.). Study of the data was done to test the significant difference between groups. Analysis of data was completed in three steps; two-way ANOVA test was used to detect impact of two independent factors on dependent continuous parametric variable. One-way ANOVA was conducted for the comparison between all groups. Tukey test for multiple comparisons was also performed and revealed statistically significant difference among groups. Student $t$-test was also used to compare each two independent groups.

\section{RESULTS}

The individual retention means and their standard deviations for all tested groups are summarized in Table 1. The maximum retention force at the time of debonding reported for titanium implants was for the conventional resin cement group (CR) $(630.38 \pm 83.0 \mathrm{~N})$ while the lowest one was reported for glass ionomer cement (GI) $(191.25 \pm 22.33 \mathrm{~N})$.

For zirconia implants, the highest reported value was for the conventional resin cement group (CR) $(443.13 \pm 67.77 \mathrm{~N})$ while the lowest one was reported for glass ionomer cement (GI) $(129.64 \pm 15.94 \mathrm{~N})$. The type of cement material significantly affected the retention force values for all implants $(\mathrm{F}=$ 142.990, $\mathrm{P}<.001$ ) (Figure 3).
Two-way ANOVA revealed a statistical significant difference between both implant material type (titanium \& zirconia), $(\mathrm{F}=79.33$, $P<.001)$ and between cement types(GI, RG, $\mathrm{SA} \& \mathrm{CR})(\mathrm{F}=142.990, \mathrm{P}<.001)$. One-way ANOVA revealed that the mean bond strength values of the titanium specimens were higher than those of the zirconia specimens. Tukey test denoted that there was no significant difference between RC and SA groups. Student $t$-test revealed that CR group displayed a higher mean bond strength than the others on both titanium and zirconia implants $(\mathrm{t}=4.94$, $P<.001)$. Glass ionomer group displayed the lowest mean bond strength than the others on both $\mathrm{T}$ and $\mathrm{Z}$ groups $(\mathrm{t}=6.35, P<.001)$.

Failure mode was assessed, and the result was summarized in Table 2. The most observed type was the mixed failure in both implants. Furthermore, with titanium implants cohesive failure (Figure 4) was more observed than with zirconia implants.

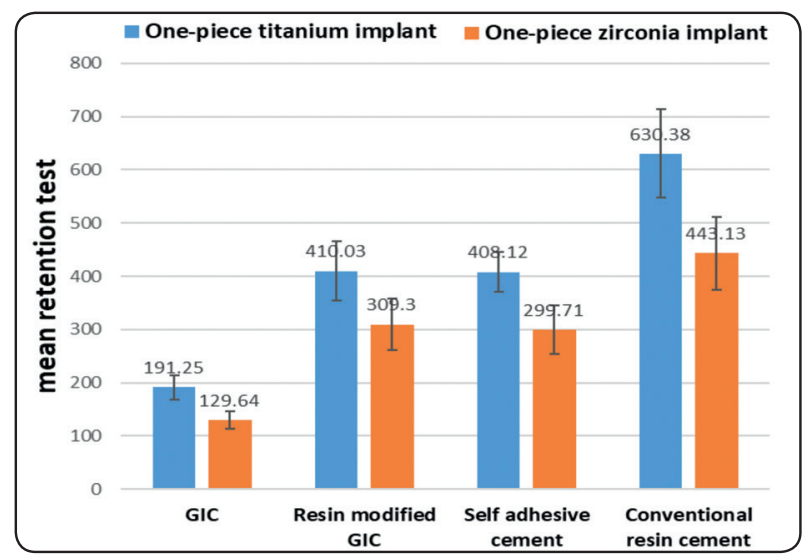

Fig. (3) Statistical summary data for pull-out retention.

TABLE (1): Means and standard deviations (in N) for bond strength of all groups (One way ANOVA and Post Hoc Tukey tests)

\begin{tabular}{|c|c|c|c|c|c|}
\hline & GI group & RG group & SA group & CR group & test of sig. \\
\hline Titanium implant & $191.25 \pm 22.33$ & $410.03 \pm 55.71^{\mathrm{a}}$ & $408.12 \pm 37.29^{\mathrm{a}}$ & $630.38 \pm 83.0$ & $\begin{array}{c}\mathrm{F}=86.55 \\
\mathrm{P}<0.001^{*}\end{array}$ \\
\hline Zirconia implant & $129.64 \pm 15.94$ & $309.30 \pm 47.87^{\mathrm{a}}$ & $299.71 \pm 46.16^{\mathrm{a}}$ & $443.13 \pm 67.77$ & $\begin{array}{c}\mathrm{F}=56.98 \\
\mathrm{P}<0.001^{*}\end{array}$ \\
\hline
\end{tabular}

Post Hoc Tukey test, the same superscripts indicate insignificant different pairs of values in same row. 
TABLE (2): Distribution of the failure mode among the studied groups.

\begin{tabular}{|c|c|c|c|c|c|c|c|c|c|c|}
\hline \multirow{2}{*}{ Type } & \multicolumn{4}{|c|}{ Titanium implant } & $\begin{array}{l}\text { Test of } \\
\text { sio }\end{array}$ & \multicolumn{4}{|c|}{ Zirconia implant } & Test of \\
\hline & GI & RG & SA & CR & \multirow{4}{*}{$P=0.171$} & GI & RG & SA & CR & \multirow{4}{*}{$P=0.082$} \\
\hline I & $\begin{array}{c}2 \\
(25.0 \%)\end{array}$ & $\begin{array}{c}2 \\
(25.0 \%)\end{array}$ & $\begin{array}{c}1 \\
(12.5 \%)\end{array}$ & $\begin{array}{c}2 \\
(25.0 \%)\end{array}$ & & $\begin{array}{c}3 \\
(37.5 \%)\end{array}$ & $\begin{array}{c}2 \\
(25.0 \%)\end{array}$ & $\begin{array}{c}2 \\
(25.0 \%)\end{array}$ & $\begin{array}{c}1 \\
(12.5 \%)\end{array}$ & \\
\hline II & $\begin{array}{c}2 \\
(25.0 \%)\end{array}$ & $\begin{array}{c}3 \\
(37.5 \%)\end{array}$ & $\begin{array}{c}3 \\
(37.5 \%)\end{array}$ & $\begin{array}{c}4 \\
(50.0 \%)\end{array}$ & & $\begin{array}{c}0 \\
(0 \%)\end{array}$ & $\begin{array}{c}2 \\
(25.0 \%)\end{array}$ & $\begin{array}{c}1 \\
(12.5 \%)\end{array}$ & $\begin{array}{c}3 \\
(37.5 \%)\end{array}$ & \\
\hline III & $\begin{array}{c}4 \\
(50.0 \%)\end{array}$ & $\begin{array}{c}3 \\
(37.5 \%)\end{array}$ & $\begin{array}{c}4 \\
(50.0 \%)\end{array}$ & $\begin{array}{c}2 \\
(25.0 \%)\end{array}$ & & $\begin{array}{c}5 \\
(62.5 \%)\end{array}$ & $\begin{array}{c}4 \\
(50.0 \%)\end{array}$ & $\begin{array}{c}5 \\
(62.5 \%)\end{array}$ & $\begin{array}{c}4 \\
(50.0 \%)\end{array}$ & \\
\hline
\end{tabular}

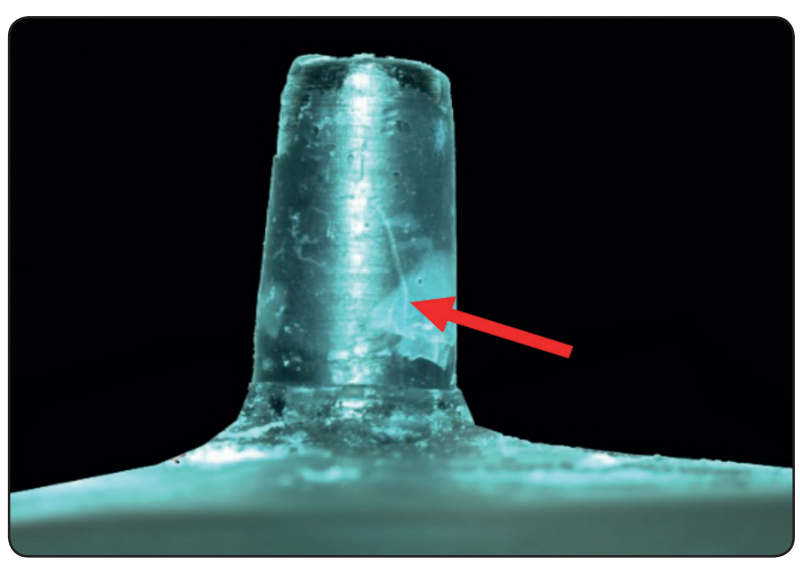

Fig. (4): Cohesive failure in titanium implants.

\section{DISCUSSION}

One-piece implant design was used in this study to evaluate the pull-out retention with crown restoration as it represents an interesting option with the increased popularity of immediate loading. ${ }^{44}$ Zirconia implants were introduced long time $\mathrm{ago}^{45}$ to solve the problems of titanium implants such as dark color of titanium and its hazard of a grayish shadow of the implant through the periimplant gingiva, mainly in the esthetic zone. Yttriastabilized tetragonal zirconia polycrystal was used in this study to fabricate the superstructure crowns restoring the one-piece implants as it is considered the recommended restorative material because of its high biocompatibility, mechanical properties and high esthetic properties. ${ }^{26}$ Materials used for cementation of indirect restorations were classified classically as temporary or permanent luting materials; the latter includes zinc phosphate, glass-ionomer, and resin cements. ${ }^{29}$ In this study, Glass ionomer cement was used in comparison with resin cements to evaluate bonding with zirconia crowns as it achieved higher bond strength as a conventional cement than zinc phosphate and zinc polycarboxylate cement in previous studies..$^{40,42,46}$

Based on the findings of this study, the first hypothesis that cement type may influence the pull-out retention values was accepted. The cement type influenced the pull-out retention values of crowns cemented to both titanium and zirconia implants as both conventional and adhesive resin cements possessed higher retention force than did glass ionomer and resin modified glass ionomer ones. This may be attributed to the action of phosphate monomer present in the composition of the self-adhesive resin cement investigated in this analysis and the application of adhesive primer containing MDP with conventional resin cement. This monomer has a longer - $\left(\mathrm{CH}_{2}\right)$ chain than other monomers of phosphate acid; ${ }^{47}$ which produces higher bond strength values to both implants than other cements. ${ }^{48}$ These results were in agreement 
with earlier investigations ${ }^{29,49}$ which have also confirmed extra promising adhesive bond force of conventional resin cement comparative to selfadhesive sorts to Y-TZP, particularly after artificial aging. However, it disagreed with Blender et $\mathrm{al}^{40}$ who reported that self-adhesive resin cement has higher retention force than conventional resin cement, this may be due to the use of different types of cements with zirconia implants only.

In the present study, the second null hypothesis was also accepted, as the titanium implants possessed higher bond strength values than did the zirconia implants which agreed with other studies ${ }^{50,51}$. These results may be attributed to the surface hardness of the zirconia material, which is much higher comparing with that of titanium, therefore, surface treatments have less effect on the zirconia surface..$^{52}$

Although it is problematic to accomplish a satisfactory bond to zirconia ${ }^{27}$ the tested selfadhesive and conventional resin cements exhibited retentive forces $299.71 \pm 46.16 \mathrm{~N}$ and $443.13 \pm 67.77$ $\mathrm{N}$ respectively. Resin modified glass ionomer cement produced relative retentive value near to those of self-adhesive resin cements despite it lacks monomers with phosphate group. This may be due to the micromechanical holding in the retentive irregularities of zirconia, or it may result from the vacuum effect which is produced by the close-fitting of the polymerized cement layer to the implant. In this study, glass ionomer cement has slightly lower retention values as it depends on carboxyl groups which make weak bond with zirconia, as previously stated. ${ }^{41}$ These findings were agreed with the results of Sellers et $\mathrm{al}^{53}$ although they used lithium disilicate crowns bonded to zirconia abutments. This was refused by other study ${ }^{40}$ which compared different types of luting agents for cementation of zirconia crowns to zirconia implant and the bond strengths were ranked as the following: glass ionomer cements $>$ self-adhesive resin-based luting agents $>$ resinbased adhesive luting agents $>$ phosphate cement $>$ polycarboxylate cement $>$ temporary cements. This difference may be due to the use of different types of cements with zirconia implants only.

Bonding of superstructure crown to implant depends on three mechanisms, in addition to preparation method and crown fit. Firstly, mechanically through micro-retentive undercuts on the roughened surfaces of crown and implant. Secondly, a closefitting of the superstructure crown to the implant abutment which produces a vacuum effect. Thirdly, by chemical bonding of the cement to the ceramic through hydroxyl groups ${ }^{54}$ or phosphate groups. ${ }^{55}$

Failure mode was easily determined by evaluation of the de-bonded surfaces, mixed type of failure was commonly observed in this current study. Nonetheless, it was observed that adhesive mode of failure decreased with conventional resin cements. Also, it was detected that most of titanium groups displayed cohesive failure which pointed to a more stable attachment of cement material to the titanium implants comparable with zirconia implants which agreed with other studies..$^{40,41,50}$

Subsequently, the general concurrence with investigation findings allowed determining that the ordering of the cements in the existing study is valid. At that point, the present and earlier studies offer a scenario of the bonding manners of different cements to one-piece implants that may be used as a guide until clinical studies are accompanied.

\section{CONCLUSIONS}

The following conclusions have been drawn within the restrictions of the present study:

1. Adhesive resin cements produced the greatest bond strength with both titanium and zirconia implants than did glass ionomer cements and self-adhesive one, moreover, the conventional glass ionomer cement showed the lowest bond strength.

2. Titanium implants had greater bonding strength with zirconia superstructure than did zirconia implants regardless the type of luting cement. 


\section{REFERENCES}

1. Bosshardt DD, Chappuis V, Buser D: Osseointegration of titanium, titanium alloy and zirconia dental implants: Current knowledge and open questions. Periodontol 2000 2017;73(1):22-40.

2. Osman RB, Swain MV: A critical review of dental implant materials with an emphasis on titanium versus zirconia. Materials. 2015;8(3):932-958.

3. Frisken K, Dandie G, Lugowski S, Jordan G: A study of titanium release into body organs following the insertion of single threaded screw implants into the mandibles of sheep. Aust Dent J. 2002;47(3):214-217.

4. Olmedo D, Fernández MM, Guglielmotti MB, Cabrini RL: Macrophages related to dental implant failure. Implant Dent. 2003;12(1):75-80.

5. de Graaf NP, Feilzer AJ, Kleverlaan CJ, Bontkes H, Gibbs S, Rustemeyer T: A retrospective study on titanium sensitivity: Patch test materials and manifestations. Contact dermatitis. 2018;79(2):85-90

6. Andreiotelli M, Wenz HJ, Kohal RJ: Are ceramic implants a viable alternative to titanium implants? A systematic literature review. Clin oral implants Res. 2009; 20:32-47.

7. Kniha K, Kniha H, Grunert I, Edelhoff D, Hölzle F, Modabber A: Esthetic evaluation of maxillary single-tooth zirconia implants in the esthetic zone. Int $\mathrm{J}$ of Periodontics \& Restorative Dent. 2019;39(5)

8. Bona AD, Pecho OE, Alessandretti R: Zirconia as a dental biomaterial. Materials. 2015;8(8):4978-4991.

9. Scarano A, Piattelli M, Caputi S, Favero GA, Piattelli A: Bacterial adhesion on commercially pure titanium and zirconium oxide disks: An in vivo human study. J Periodontol. 2004;75(2):292-296.

10. Karl M, Scherg S, Grobecker-Karl T: Fracture of reduceddiameter zirconia dental implants following repeated insertion. Int J Oral Maxillofac Implants. 2017;32(5):971975.

11. Hashim D, Cionca N, Courvoisier DS, Mombelli A: A systematic review of the clinical survival of zirconia implants. Clin Oral Investig. 2016;20(7):1403-1417.

12. Grassi FR, Capogreco M, Consonni D, Bilardi G, Buti J, Kalemaj Z: Immediate occlusal loading of one-piece zirconia implants: Five-year radiographic and clinical evaluation. Int J Oral Maxillofac Implants. 2015;30(3).
13. Thoma DS, Benic GI, Muñoz F, Kohal R, Sanz Martin I, Cantalapiedra AG, Hämmerle CH, Jung RE: Histological analysis of loaded zirconia and titanium dental implants: An experimental study in the dog mandible. J Clin Periodontol. 2015;42(10):967-975.

14. Pieralli S, Kohal R-J, Hernandez EL, Doerken S, Spies $\mathrm{BC}$ : Osseointegration of zirconia dental implants in animal investigations: A systematic review and meta-analysis. Dent Mater. 2018;34(2):171-182.

15. Balmer M, Spies BC, Kohal RJ, Hämmerle CHF, Vach K, Jung RE: Zirconia implants restored with single crowns or fixed dental prostheses: 5-year results of a prospective cohort investigation. Clin Oral Implants Res. 2020;31(5):452-462.

16. Adánez $\mathrm{MH}$, Nishihara $\mathrm{H}$, Att $\mathrm{W}$ : A systematic review and meta-analysis on the clinical outcome of zirconia implantrestoration complex. J Prosthodon Res. 2018;62(4):397406.

17. Oliva J, Oliva X, Oliva JD: Five-year success rate of 831 consecutively placed zirconia dental implants in humans: A comparison of three different rough surfaces. Int J Oral Maxillofac Implants. 2010;25(2).

18. Bollen C: Zirconia: The material of choice in implant dentistry? An update. J Dent Heal Oral Disord Ther. 2017;6(6):1-4

19. Sanz M, Noguerol B, Sanz-Sanchez I, Hammerle CH, Schliephake H, Renouard F, Sicilia A, Committee $\mathrm{S}$, Cordaro L, Jung R: European association for osseointegration delphi study on the trends in implant dentistry in europe for the year 2030. Clin Oral Implants Res. 2019;30(5):476-486.

20. Liu $\mathrm{M}$, He L, Wang $\mathrm{H}$ : Clinical and radiographic performance of one-piece and two-piece implant: A systematic review and meta-analysis. J Prosthodon Res. 2021: JPOR_2019_2436.

21. Schiessl C, Schaefer L, Winter C, Fuerst J, Rosentritt M, Zeman F, Behr M: Factors determining the retentiveness of luting agents used with metal-and ceramic-based implant components. Clin Oral Investig. 2013;17(4):1179-1190.

22. Stawarczyk B, Beuer F, Ender A, Roos M, Edelhoff D, Wimmer T: Influence of cementation and cement type on the fracture load testing methodology of anterior crowns made of different materials. Dent Mater. 2013;32(6):888895. 
23. Tanış MÇ, Akçaboy C: Effects of different surface treatment methods and mdp monomer on resin cementation of zirconia ceramics an in vitro study. J Lasers Med Sci. 2015;6(4):174.

24. Palacios RP, Johnson GH, Phillips KM, Raigrodski AJ: Retention of zirconium oxide ceramic crowns with three types of cement. J Prosthet Dent. 2006;96(2):104-114.

25. Uo M, Sjögren G, Sundh A, Goto M, Watari F, Bergman M: Effect of surface condition of dental zirconia ceramic (denzir) on bonding. Dent Mater. 2006;25(3):626-631.

26. Gracis S, Thompson VP, Ferencz JL, Silva NR, Bonfante EA: A new classification system for all-ceramic and ceramic-like restorative materials. Int J Prosthodont. 2015;28(3).

27. Mahmoodi N, Hooshmand T, Heidari S, Khoshro K: Effect of sandblasting, silica coating, and laser treatment on the microtensile bond strength of a dental zirconia ceramic to resin cements. Lasers Med Sci. 2016;31(2):205-211.

28. Inokoshi M, De Munck J, Minakuchi S, Van Meerbeek B: Meta-analysis of bonding effectiveness to zirconia ceramics. J Dent Res. 2014;93(4):329-334.

29. Özcan M, Bernasconi M: Adhesion to zirconia used for dental restorations: A systematic review and meta-analysis. J Adhes Dent. 2015;17(1).

30. Wolfart M, Lehmann F, Wolfart S, Kern M: Durability of the resin bond strength to zirconia ceramic after using different surface conditioning methods. Dent Mater. 2007;23(1):45-50.

31. Dérand P, Derand T: Bond strength of luting cements to zirconium oxide ceramics. Int J Prosthodont. 2000;13(2).

32. Lin J, Shinya A, Gomi H, Shinya A: Effect of self-adhesive resin cement and tribochemical treatment on bond strength to zirconia. Int J Oral Sci. 2010;2(1):28-34.

33. Ernst C-P, Cohnen U, Stender E, Willershausen B: In vitro retentive strength of zirconium oxide ceramic crowns using different luting agents. J Prosthet Dent. 2005;93(6):551-558.

34. Inokoshi M, Poitevin A, De Munck J, Minakuchi S, Van Meerbeek B: Bonding effectiveness to different chemically pre-treated dental zirconia. Clin Oral Investig. 2014;18(7):1803-1812.

35. Papia E, Larsson C, du Toit M, von Steyern PV: Bonding between oxide ceramics and adhesive cement systems: A systematic review. J Biomed Mater Res B Appl Biomater. 2014;102(2):395-413.
36. Gomes AL, Ramos JC, Santos-del Riego S, Montero J, Albaladejo A: Thermocycling effect on microshear bond strength to zirconia ceramic using er: Yag and tribochemical silica coating as surface conditioning. Lasers Med Sci. 2015;30(2):787-795.

37. Otani A, Amaral M, May LG, Cesar PF, Valandro LF: A critical evaluation of bond strength tests for the assessment of bonding to y-tzp. Dent Mater. 2015;31(6):648-656.

38. Hu M, Weiger R, Fischer J: Comparison of two test designs for evaluating the shear bond strength of resin composite cements. Dent Mater. 2016;32(2):223-232.

39. Edelhoff D, Özcan M: To what extent does the longevity of fixed dental prostheses depend on the function of the cement? Working group 4 materials: Cementation. Clin Oral Implants Res. 2007; 18: 193-204.

40. Blender SM, Mellinghoff J, Gröller SB, Schnutenhaus S, Kuhn K, Luthardt RG, Rudolph H: Effects of abutment height and type of cements on bond strength of monolithic zirconia single crowns luted to one-piece zirconia implants. Int J Prosthodont 2021. DOI: 10.11607

41. Rohr N, Brunner S, Märtin S, Fischer J: Influence of cement type and ceramic primer on retention of polymerinfiltrated ceramic crowns to a one-piece zirconia implant. J Prosthet Dent. 2018;119(1):138-145.

42. Lepe X, Streiff KR, Johnson GH: Long-term retention of zirconia crowns cemented with current automixed cements. J Prosthet Dent. 2020

43. Rohr N, Coldea A, Zitzmann NU, Fischer J: Loading capacity of zirconia implant supported hybrid ceramic crowns. Dent Mater.2015;31(12):e279-e288.

44. Hahn JA: Clinical and radiographic evaluation of onepiece implants used for immediate function. J Oral Implantol. 2007;33(3):152-155.

45. Scarano A, Di Carlo F, Quaranta M, Piattelli A: Bone response to zirconia ceramic implants: An experimental study in rabbits. J Oral Implantol. 2003;29(1):8-12.

46. Heintze S: Crown pull-off test (crown retention test) to evaluate the bonding effectiveness of luting agents. Dent Mater. 2010;26(3):193-206.

47. Yoshida K, Tsuo Y, Atsuta M: Bonding of dual-cured resin cement to zirconia ceramic sing phosphate acid ester monomer and zirconate coupler. J Biomed Mater Res B Appl Biomateri. 2006;77(1):28-33. 
48. Heintze SD: Clinical relevance of tests on bond strength, microleakage and marginal adaptation. Dent Mater. 2013;29(1):59-84.

49. Son Y-H, Han C-H, Kim S: Influence of internal-gap width and cement type on the retentive force of zirconia copings in pullout testing. J Dent. 2012;40(10):866-872.

50. Turker N, Özarslan MM, Buyukkaplan US, Başar EK: Effect of different surface treatments applied to short zirconia and titanium abutments. Int J Oral Maxillofac Implants. 2020;35(5).

51. Silva CE, Soares S, Machado CM, Bergamo ET, Coelho PG, Witek L, Ramalho IS, Jalkh EB, Bonfante EA: Effect of $\mathrm{cad} / \mathrm{cam}$ abutment height and cement type on the retention of zirconia crowns. Implant Dent. 2018;27(5):582-587.
52. Kern M: Bonding to oxide ceramics-laboratory testing versus clinical outcome. Dent Mater. 2015;31(1):8-14.

53. Sellers K, Powers JM, Kiat-Amnuay S: Retentive strength of implant-supported cad-cam lithium disilicate crowns on zirconia custom abutments using 6 different cements. J Prosthet Dent. 2017;117(2):247-252.

54. Kim S-M, Yoon J-Y, Lee M-H, Oh N-S: The effect of resin cements and primer on retentive force of zirconia copings bonded to zirconia abutments with insufficient retention. J Adv Prosthodont. 2013;5(2):198.

55. Thompson JY, Stoner BR, Piascik JR, Smith R: Adhesion/ cementation to zirconia and other non-silicate ceramics: Where are we now? Dent Mater. 2011;27(1):71-82. 